\title{
Cidadania e qualidade de vida dos portadores de transtornos psiquiátricos: contradições e racionalidade
}

CITIZENSHIP AND LIFE QUALITY OF PORTERS OF PSYCHIATRICS PERTURBATIONS: CONTRADICTIONS AND RATIONALITY

CIUDADANÍA Y CALIDAD DE VIDA DE LOS PORTADORES DE TRASTORNOS SIQUIÁTRICOS: CONTRADICCIONES YRACIONALIDAD

Josicelia Dumêt Fernandes ${ }^{1}$, Maria Rita Oliveira², Juliana Fernandes ${ }^{3}$

\section{RESUMO}

Este estudo consiste num espaço de reflexão sobre a questão da cidadania e qualidade de vida dos portadores de transtornos psíquicos, tomando como eixo as transformações ocorridas na relação da sociedade com esses indivíduos, explicitando suas contradições e racionalidade. Aponta os desafios a serem superados na construção da cidadania e qualidade de vida dessas pessoas.

\section{PALAVRAS-CHAVE}

Saúde mental. Cidadania. Qualidade de vida.

\author{
ABSTRACT \\ This study consists in \\ reflection about the questions \\ of citizenship and life quality \\ of porters of psychic \\ perturbation, considering the \\ transformations occurred on \\ the relation between the \\ society and these porters, \\ showing its contradictions \\ and rationality. This study \\ indicates the challenges to be \\ surpassed on the construction \\ of citizenship a life quality \\ of these people.
}

\section{KEYWORDS}

Mental health. Citizenshi. Quality of life.

\section{RESUMEN}

Este estudio consiste en espacio de reflexión sobre la ciudadanía y calidad de vida de los portadores de trastornos síquicos, tomando como eje las transformaciones ocurridas en la relación de la sociedad con esses individuos, explicitando sus contradicciones y racionalidad. Indica los desafios a ser superados en la construcción de la ciudadanía y calidad de vida de estas personas.

\section{PALABRAS-CLAVE}

Salude mental. Ciudadanía. Calidad de vida.
1 Professora Titular da Escola de Enfermagem da Universidade Federal da Bahia. dumet@ufba.br 2 Professora da Escola de Enfermagem da Universidade Federal da Bahia.

mo2@uol.com.br

3 Estudante de graduação da Universidade Federal da Bahia. Bolsista de Iniciação Científica. 


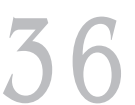

Rev Esc Enferm USP 2003; 37(2): 35-42

\section{INTRODUÇÃO}

O presente estudo se constitui num trabalho de reflexão sobre a questão da Cidadania e Qualidade de Vida (CQV) dos portadores de transtornos psíquicos. Tem como eixo central, as transformações ocorridas na relação da sociedade com esses indivíduos, reveladas ao longo do caminhar da Psiquiatria, bem como suas contradições e racionalidade. Parte do entendimento de que essas transformações estão articuladas àquelas que, dinamicamente, movem a sociedade brasileira e a Psiquiatria, estando, portanto, tangenciado por uma atividade de (re)construção de etapas de apreciação do ontem, do hoje e de uma inexorável perspectiva do amanhã.

Nesse direcionamento, discute-se alguns aspectos das contradições que vêm direcionando a inserção do louco na sociedade, desde a institucionalização da loucura até os dias atuais, quando são operacionalizados os princípios da Reforma Psiquiátrica, investigando-se a racionalidade e contradições que vêm direcionando o discurso da CQV do doente mental.

Parte-se do entendimento de que a trajetória da cidadania da loucura é, também, a trajetória de um saber e de uma prática apreendidos e arquitetados coletivamente; de que a condição social de cidadania e qualidade de vida não se inscreve apenas no corpo desses indivíduos por razões políticas e assistenciais de ordem conjuntural, mas, também, por razões de ordem estrutural, instituídas no processo histórico da doença mental; de que o pensamento sócio-político-cultural de cada momento histórico molda as ações da sociedade com a loucura; de que o portador de transtorno mental, como todo ser humano, tem potencialidades e talentos que, para serem explicitados, necessitam de condições favoráveis que caracterizem o exercício da cidadania.

Sob essa ótica, foram levantadas as seguintes questões norteadoras para o presente estudo: Como se configura a relação da sociedade com a cidadania e qualidade de vida do portador de transtorno mental? Quais as contradições e racionalidade que orientam o discurso da cidadania da loucura?

Buscando respostas a essas questões, foram definidos, para este estudo, os seguintes objetivos:
- Configurar o processo de construção da cidadania e qualidade de vida do indivíduo portador de transtorno mental, na sociedade brasileira.

- Investigar as contradições e racionalidade que vêm direcionando a inserção do portador de transtorno psíquico na sociedade.

\section{ENTENDENDO O SIGNIFICADO DE CIDADANIA E QUALIDADE DE VIDA}

Toda formação social necessita, para seu exercício cotidiano, de uma institucionalidade específica que se revela na concepção de cidadania - expressão ligada à idéia de democracia e igualdades formais perante a lei ${ }^{(1)}$.

O conceito de cidadania, enquanto direito a ter direitos, tem se prestado a diversas interpretações. Acerca dessas interpretações, verifica-se que a cidadania seria composta pelos direitos civis e políticos (direitos de primeira geração) e direitos sociais (direitos de segunda geração). Os direitos civis correspondem aos direitos individuais de liberdade, propriedade, de ir e vir, direito à vida, segurança, dentre outros. Já os direitos políticos dizem respeito à liberdade de associação e reunião, de organização política e sindical, à participação política e eleitoral, ao sufrágio universal. São também chamados de direitos individuais exercidos coletivamente e válidos para o ser humano abstrato ${ }^{(2)}$.

Os direitos de segunda geração envolvem os direitos sociais, econômicos ou de créditos e reportam-se aos direitos ao trabalho, saúde, educação, aposentadoria, seguro-desemprego, enfim, a garantia, pela intervenção positiva do Estado, de acesso aos meios necessários à vida e ao bem estar social ${ }^{(2-3)}$.

Existem, também, os direitos de terceira geração, que são aqueles que têm como titular não o indivíduo, mas grupos humanos como o povo, a nação, coletividades étnicas ou a própria humanidade. É o caso do direito à autodeterminação dos povos, ao desenvolvimento, à paz, ao meio ambiente, dentre outros. Compreendem os direitos relativos aos interesses difusos, a exemplo do direito ao meio ambiente, direito do consumidor, além dos direitos das mulheres, das crianças, das minorias étnicas, dos jovens, anciãos, dentre outros ${ }^{(2)}$. 
Atualmente, já se falam de direitos de quarta geração, relativos a bioética, para impedir a destruição da vida e regular a criação de novas formas de vida em laboratório, promovidas pela engenharia genética ${ }^{(2)}$.

A consciência dos direitos iguais está intrinsecamente relacionada ao sentir-se igual aos outros. Significa tomar decisões, opinar sobre sua vida profissional, social, amorosa e familiar. Significa fazer-se sujeito e, para isto, necessita manejar o conhecimento, apropriar-se dele e reconstruí-lo ${ }^{(4)}$.

Os direitos civis e políticos, considerados direitos fundamentais, são universais e válidos para o ser humano abstrato. Todos os cidadãos têm os mesmos direitos, independentemente dos seus atributos pessoais. Mas essa generalização e abstração possíveis e necessárias, em relação aos direitos civis, não têm sido observadas em relação aos direitos sociais, ou seja, verifica-se uma supremacia dos direitos civis e políticos sobre os direitos sociais ${ }^{(3,5)}$.

Por outro lado, observa-se que o cotidiano do exercício desses direitos está imediatamente intrincado com a questão da qualidade de vida, que vem sendo considerada como um construto que abrange sentimentos e estados subjetivos da satisfação das pessoas em seu viver diário.

Assim, pensar CQV dos indivíduos portadores de transtornos mentais, leva à reflexão da realidade multifacetada que se nos apresenta. A possibilidade de CQV para esses indivíduos implica na garantia de seus direitos de igualdade, saúde, trabalho, transporte, educação, lazer, enfim, de ações coletivas de uma sociedade e não apenas de uma questão individual do portador de transtorno mental.

Como garantir esses direitos no mundo de hoje onde está desaparecendo, de maneira mais essencial, a própria noção de direito a ter direitos? Como se dá a inserção social dos cidadãos com comprometimento mental, num país com baixa magnitude dos gastos em saúde e com o movimento de minimização da atuação do Estado em relação aos compromissos sociais da sociedade? Numa sociedade neoliberal, patrocinada pela implementação do Estado Mínimo, quais os direitos que estão compondo o exercício da cidadania dos usuários dos serviços de saúde mental?
Enquanto os direitos civis e políticos exigiriam, para sua plena realização, um Estado Mínimo, os direitos sociais demandariam uma presença mais forte do Estado para serem realizados. Assim, a tese atual de Estado Mínimo - patrocinada pelo neoliberalismo corresponde não apenas a uma discussão meramente quantitativa, mas envolve estratégias diferenciadas dos diversos direitos que compõem o conceito de cidadania e dos atores sociais respectivos ${ }^{(2)}$.

Num país com desigualdades acentuadas, CQV se constitui numa questão social, na medida em que esse binômio é representado por um contexto de dimensões variadas onde se incluem percepções, experiências de vida, oportunidades sociais, recursos sócio-econômicos, acesso à educação, saúde, transporte, habitação, dentre outros.

CQV não pode ser visualizada, destarte, como uma questão individual, na qual a responsabilidade é única e exclusivamente do indivíduo. CQV é uma questão coletiva, onde se faz necessária a explicitação de um conjunto de necessidades fundamentais que implicam na definição de responsabilidades sociais, o que transcende o campo de intervenção em saúde.

Nessa perspectiva, importa entender as contradições estruturais e conjunturais da relação da sociedade com a cidadania e qualidade de vida dos portadores de transtornos psíquicos no mundo atual.

\section{LOUCURA, CIDADANIA E QUALIDADE DE VIDA: CONTRADIÇÕES E RACIONALIDADE}

Na modernidade, institui-se, no regime político, um modelo universal de direitos sociais (liberdade, igualdade e fraternidade), sendo os indivíduos considerados iguais perante a lei (apesar de suas diferenças). Contemporaneamente, o trabalho e a produção determinam a construção social do homem como um ser racional e produtivo.

O louco que, até então, era marginalizado e considerado desprovido da razão, da vontade e economicamente improdutivo, passa a ser visualizado como passível de ser restaurado na sua condição de sujeito do contrato social, desde que sua natureza passional fosse submetida a uma correção através de um processo terapêutico que se daria através do asilamento.
Cidadania e qualidade de vida dos portadores de transtornos psiquiátricos: contradições e racionalidade 
Josicélia Dumêt Fernandes Maria Rita Oliveira Juliana Fernandes

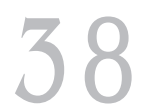

Rev Esc Enferm USP 2003; 37(2): 35-42.
Reconhece-se a especificidade do louco que passa a ter o direito de ser cuidado medicamente e ser protegido pelo Estado. Privase o louco da sua liberdade, mas, por outro lado, procura-se transformá-lo num indivíduo que "poderá" ser transformado num sujeito instituído de razão e vontade.

Ao se considerar a necessidade do hospício como um local para o tratamento da loucura, o saber da época indica que o comportamento do louco passa a ser patologizado e, destarte, medicalizável. O louco passa a ser considerado doente, ressalvando-se suas particularidades de não responsável, de sua incapacidade para inserir-se nas normas da vida civil e social, continuando, contudo, a necessidade de manter-se a ideologia do isolamento. A ele é instituída, progressivamente, uma postura de docilidade e obediência ao poder asilar, através de tratamentos e técnicas de sociabilidade. A figura do louco passa a ser transformada na figura de um ser social, instituída de razão e vontade, na sua condição de sujeito instituído de razão e vontade, podendo, então, inscrever-se no espaço social ${ }^{(6)}$.

Com o incremento dos psicofármacos, na década de 50, aprimora-se a regulação dos sintomas da loucura e o controle orgânico do desvio para o estabelecimento do sujeito da razão que, através do exercício de sua vontade, poderia ser inserido no espaço social como cidadão. Por outro lado, através desses mesmos psicofármacos realiza-se o amordaçamento bioquímico desse indivíduo.

Essa realidade revela uma contradição estrutural entre o doente mental e a cidadania. A Psiquiatria, ao tempo em que possibilita ao louco o direito à assistência médica e de cuidados terapêuticos, retira dele as demais condições de cidadania. Se por um lado, confere-se ao louco o estatuto social de doente com direito à assistência e a tratamento, sob a proteção do Estado, por outro lado autoriza-se a exclusão social desse indivíduo, destituindo-o de seus direitos sociais, isto é, sua condição política de cidadania plena. Essa é, portanto, uma contradição estrutural que se inscreve na constituição histórica da doença mental.

Através de reformas institucionais como a Comunidade Terapêutica e a Psicoterapia Institucional busca-se a humanização dos asilos pela organização coletiva do trabalho e pedagogia da sociabilidade. Através de atividades praxiterápicas e de grupos operativos, os doentes passam a aprender as regras das relações interpessoais do espaço social, sendo instituídos como agentes sociais de sua existência asilar.

A Comunidade Terapêutica, entretanto, configura sua fragilidade na impossibilidade de dialetizar o dentro e o fora do asilo, ou seja, na impossibilidade de encontrar uma forma possível de inserção da loucura fora do espaço asilar, no espaço social.

Já a Psiquiatria Comunitária, dos anos 60 e 70 , busca a resolução da questão dentro/fora do asilo, tentando impedir as internações, através de medidas que favorecessem o diagnóstico precoce e tratamento eficaz nos ambulatórios, além de práticas pedagógicas, ditas preventivas. Com isto se pretendia produzir positivamente a saúde mental como valor máximo para a constituição da cidadania e a regulação do desvio social. As ações de promoção da saúde mental se estabelecem como reguladoras da marginalidade social e das regras básicas para a cidadania. As condições essenciais para o estabelecimento da saúde mental seriam as mesmas que definiriam a cidadania - $o$ indivíduo, para ser cidadão, deveria ter restabelecido sua saúde mental.

Observa-se, portanto, a contradição de um projeto que pretende promover a desalienação asilar da loucura em busca de um lugar social para a sua inserção; a contradição de um projeto de produção da saúde mental que se identifica diretamente com o projeto de produção do cidadão ideal para o espaço social, como se a instauração da cidadania para os loucos possibilitasse o seu reconhecimento como sujeitos da razão e da vontade.

Em que pesem as tentativas de ruptura da Psiquiatria com o espaço asilar, na década de 70, o fazer em saúde mental continuava sendo denunciado como precário, caótico, caracterizando-se pela utilização de hospitais tradicionais, escassez de serviços ambulatoriais (ambos restritos, primordialmente, ao consumo medicamentoso), internações longas e hospitalizações desnecessárias, altas taxas de reinternações com cronificação de doentes, tornando a assistência dispendiosa e falha nos seus objetivos. Essa assistência, portanto, não alcançava avanços significativos nem promovia a elevação dos níveis de saúde da população, continuando uma prática de tutela custodial aos pacientes, circunscrita ao modelo hospitalocêntrico da assistência psiquiátrica ${ }^{(7-8)}$. 
Essa realidade desencadeou uma série de críticas que vão assumir importância nos anos 80, enfatizando a dívida do Estado para com os doentes mentais em função de sua longa exclusão e a conseqüente ruptura de seus laços sociais. Essas críticas colocavam a problemática da cidadania dos doentes mentais na agenda das preocupações teóricas dos trabalhadores da área da saúde mental, favorecendo um debate sobre a loucura.

A partir do final da década de 80 , surge uma série de iniciativas clamando pelo respeito aos direitos dos indivíduos com transtornos psiquiátricos, que deveriam ter reconhecida sua cidadania. Esse debate não se limitava ao interior dos muros do hospício. Ele se estendeu para toda a sociedade - para as entidades da sociedade civil e para a grande imprensa. A questão psiquiátrica (precárias condições dos hospitais psiquiátricos e distorções da política nacional de assistência psiquiátrica) tornara-se uma questão política, trazendo o debate da cidadania e direitos humanos do doente mental, além do direito a uma assistência digna, destacando-se a necessidade do respeito aos direitos fundamentais dos pacientes psiquiátricos, principalmente no que refere ao direito de viver em comunidade, de ser tratado em ambiente menos restritivo possível, de acesso à informação no que se refere a si próprio, o direito a confidenciabilidade e ao consentimento para o tratamento.

A partir daí, se fortalece o movimento da Reforma Psiquiátrica (RP) brasileira, que se apresenta como conjunto de iniciativas políticas, sociais, culturais, administrativas e jurídicas que buscam transformar a relação da sociedade para com o doente mental, através da proposta de reversão do modelo nosocomial e instauração de uma nova clínica, partindo de uma crítica contundente ao princípio de exclusão e isolamento social do paciente psiquiátrico, ancorado-se no modelo clínico fundamentado no reconhecimento de manifestações sintomáticas. Os doentes passam a ser vistos como atores/sujeitos e não mais como meros objetos de conhecimento e violência institucional. O tratamento inclui a participação do paciente na construção de projetos terapêuticos e na configuração de seu cotidiano. Os leitos de internação devem ser progressivamente diminuídos e gradativamente substituídos por formas abertas de tratamento buscando a reabilitação psicossocial, sem excluir, contudo, a possibilidade de internação ${ }^{(9-10)}$.
Essa proposta de reversão do modelo nosocomial aponta para os Núcleos de Atenção Psicossocial (NAPS) ou Centros de Atenção Psicossocial (CAPS), como estruturas abertas ao atendimento de emergências, como espaços de convivência, como locais de referência para o usuário no momento da crise, como instituições ativadoras dos recursos comunitários e da integração do paciente, família e comunidade.

Esse conjunto de iniciativas apresenta como metas: reverter a tendência hospitalocêntrica através da implantação de um sistema extra-hospitalar e multiprofissional de assistência; proibir a construção de novos hospitais psiquiátricos e o credenciamento de novos leitos nos hospitais convencionais; diminuir progressivamente os leitos de internação psiquiátrica e sua substituição progressiva por formas abertas de tratamento ou leitos psiquiátricos em hospitais gerais.

Em todas essas metas perpassa uma mais abrangente que é o resgate da cidadania do doente mental, apontando para a necessidade de delinear um outro lugar social para a loucura e enfatizando a questão da cidadania do usuário dos serviços de saúde mental.

Verifica-se, enfim, que a produção da saúde mental se identifica diretamente com o projeto de produção do cidadão para o espaço social. O impasse desse projeto encontra-se na identificação entre alienação social e loucura, como se esta fosse uma forma de alienação, e como se a instauração da cidadania para os loucos possibilitasse o seu reconhecimento positivo como sujeitos da razão e da vontade, ou seja, como se apenas a inserção do louco no espaço social lhe garantisse o exercício da cidadania e qualidade de vida com dignidade ${ }^{(6)}$.

\section{A INSERÇÃO DO LOUCO NA SOCIEDADE: APESAR DAS DESIGUALDADES...}

O binômio cidadania e qualidade de vida na pós-modernidade apresenta desafios que afetam diretamente a todos os indivíduos, inclusive os portadores de transtornos psiquiátricos que não estão imunes às conse-qüências do processo de globalização gerenciado pela macro-economia e pela comunicação de massa.

Os anos 90 se apresentaram com uma profunda e ampla reorganização política, econômica, social e ideológica, tangenciada pelo
Cidadania e qualidade de vida dos portadores de transtornos psiquiátricos: contradições e racionalidade 
Josicélia Dumêt Fernandes Maria Rita Oliveira Juliana Fernandes

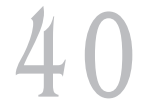

Rev Esc Enferm USP 2003; 37(2): 35-42 ideário neoliberal e o conseqüente aumento das desigualdades sociais. No bojo dessa reorganização, observa-se a transformação do espaço de discussão política em estratégias de convencimento publicitário, bem como a redefinição da cidadania pela qual o agente político se transforma em agente econômico e o cidadão em consumidor. Em seu conjunto, esse processo faz com que noções como igualdade e justiça social sejam recuadas no espaço de discussão pública e cedam lugar, de uma forma redefinida, às noções de produtividade, eficiência e qualidade, colocadas como condição de acesso a uma suposta modernidade.

É importante compreender que esse processo é parte de um processo mais amplo. Numa era de globalização e de internacionalização, esse projeto nacional não pode ser compreendido fora de sua dinâmica internacional, que traz, no seu bojo, as condições para a redução das responsabilidades do Estado na construção de sociedades mais justas e mais igualitárias.

É nesse projeto global que se insere a redefinição do setor saúde que, por sua vez, percorre uma trajetória de agravamento com a crise econômica e fiscal do país. O sonho reformista de uma saúde para todos, como direito do cidadão e dever do Estado, é aceleradamente mutilado nessa década. Por um lado, temos os fenômenos da globalização, da economia, da informatização, das tecnologias de ponta, do aumento do acesso e consumo de bens, dentre outros. Por outro lado, se configuram a explosão da fragmentação social e sua tradução em múltiplas diferenciações, o aumento do desemprego, da proletarização e conseqüente exclusão social e cultural de contingentes cada vez maiores da população.

No setor saúde, convive-se com situações extremamente conflitantes: a vida como valor supremo e a ênfase na valorização do corpo; a elevação da qualidade da expectativa de vida de algumas parcelas da população convivendo, lado a lado, com a reincidência de epidemias que assolaram o país, há dezenas de décadas atrás. O sucateamento da rede pública de assistência à saúde e a incapacidade do sistema em atender às demandas mínimas de justiça social e de cidadania têm transformado o acesso aos serviços e um atendimento digno, garantidos na Constituição Brasileira, em aspiração dos poucos que podem pagar ${ }^{(2)}$.

No âmbito da saúde mental, ao tempo em que se aprova a extinção gradual dos asilos, buscando-se a garantia dos direitos, particularmente os direitos sociais, dos portadores de transtornos mentais, não se observa, por parte do governo, uma política de financiamento para implementação das estruturas assistenciais e de apoio social que possam substituir o hospital psiquiátrico. São escassos os programas que incluem, além de recursos da área assistencial (CAPS, NAPS, sistema de atendimento às crises e recursos humanos qualificados), mecanismos de suporte social que favoreçam a convivência do portador de transtorno psíquico na sociedade. $\mathrm{O}$ conjunto de instrumentos disponíveis ainda é insuficiente, beneficiando, essencialmente, a clientela que tem possibilidade de algum suporte social, seja familiar, seja por recursos próprios como aposentadoria/benefícios, ou aqueles pacientes com melhor capacidade de adaptação social face às peculiaridades de sua condição psíquica ${ }^{(11)}$.

Para uma melhor apreensão dessa realidade, é necessário visualizar a dimensão econômica, política e social do mundo globalizado. A dimensão econômica da globalização retratase na integração dos mercados e na privatização, como sendo a panacéia do desenvolvimento. Contraditoriamente, suas conseqüências sociais são graves, na medida em que acarretam aumento do desemprego, queda dos níveis salariais, aumento da pobreza e da concentração de renda, conflitos sociais, degradação dos serviços públicos, deterioração da qualidade de vida, destruição ambiental. A dimensão política da globalização implica na impossibilidade dos Estados nacionais articularem uma política, própria, de desenvolvimento. A dimensão social da globalização diz respeito ao processo de reestruturação econômica que vem levando o mundo em desenvolvimento à fome e grandes parcelas da população ao empobrecimento. A nova ordem financeira internacional parece nutrir-se da exclusão social e degradação ambiental ${ }^{(2)}$.

Enquanto no plano internacional a economia opera basicamente livre de controles políticos, no plano nacional os governos são constrangidos a fomentar a "modernização" de suas economias, adaptando-a à chamada competitividade internacional. O resultado é o agravamento da crise social e o surgimento de grupos marginalizados gradualmente apartados do restante da sociedade ${ }^{(12)}$.

Como se pode observar, a globalização da pobreza ocorre em época de notável progresso tecnológico, com redução da oferta 
de empregos produtivos reforçando as tendências de exclusão social, com a segregação das minorias privadas de voz reconhecida na esfera pública, acarretando a erosão da força integrativa da cidadania democrática.

Como garantir CQV para o louco nessa realidade? Como fica a situação do portador de transtorno mental, com a singularidade de sua condição psíquica, para disputar um mercado de trabalho competitivo e com altas taxas de desemprego? Como fica o exercício da cidadania (exercício racional da autonomia) de indivíduos considerados, ainda, como desprovidos de razão? Como articular a reivindicação de autonomia e práticas emancipatórias com intervenções terapêuticas, cuidado e proteção?

A idéia de CQV para o portador de transtorno mental, apresenta esse indivíduo como átomo da sociabilidade, tornando possível, a aceitação de um conformismo social básico. As aparências são necessárias para que a fetiche surja como verdade. Apresenta-se o doente mental como cidadão com direitos iguais a concorrer no mercado de trabalho. Esta é, exatamente, a afirmação da impossibilidade de uma cidadania pelo trabalho numa sociedade marcada pelas desigualdades sociais.

A CQV do portador de transtorno psíquico pode se realizar no campo político, pela construção da aparência dos cidadãos abstratos, mas mantem-se, necessariamente, ausente, no campo da inclusão social. Este tem sido o processo pelo qual a sociedade e o indivíduo procuram adaptar-se mutuamente, levando-se em conta as diferenças individuais, a valorização da diversidade humana, a equiparação de oportunidades e, conseqüentemente, uma sociedade para todos ${ }^{(13)}$. Partindo desse entendimento, a inclusão do louco na sociedade implicaria em sua inclusão na escola, no trabalho, nos espaços de lazer, nos serviços de saúde, dentre outros. Implicaria, também, na adaptação da sociedade às necessidades das pessoas portadoras de transtornos mentais. Implicaria, enfim, na celebração das diferenças, direito de pertencer, sociedade humanitária, igual importância das minorias e cidadania com qualidade de vida

Nessa perspectiva, indica-se que a questão da cidadania do louco aponta, implicitamente, para uma relação de oposição, de contradição entre as noções de cidadania (e seus corolários: liberdade, igualdade, autonomia, racionalidade) e de loucura (constrangimento, diferença, dependência, irracionalidade). $\mathrm{O}$ cidadão-expres- são universal de uma subjetividade racional se contraporia ao louco, manifestação radical da singularidade subjetiva, desviante ${ }^{(14)}$.

Ora, ao se aceitar os termos do problema assim proposto, não se tem como evitar o paradoxo das diferenças. Resta dizer que o louco tem duas faces, a psicopatológica e a condição de exclusão; de um lado o universo psíquico do sujeito, do outro, o universo social do cidadão ${ }^{(15)}$.

A relação da loucura com a cidadania se caracteriza, portanto, por essa contradição. Assim, qualquer proposta de CQV para os portadores de transtornos psíquicos deve começar pelo reconhecimento desse paradoxo que caracteriza a relação da loucura com os princípios éticos da cultura ocidental.

O processo da Reforma Psiquiátrica não deve, portanto, significar apenas rearranjos nas técnicas e instituições psiquiátricas, nem, tampouco, apenas desfazer o aparato e a cultura manicomial mas, sobretudo, construir uma nova maneira da sociedade lidar com a loucura. Isto, por sua vez, implica em reinventar não só a Psiquiatria mas a própria sociedade em que vivemos. Pretender a transformação da Psiquiatria sem atacar os pontos de sustentação que a sociedade lhe oferece é cair na ilusão de que pela técnica se poderia modificar realidades cuja natureza - histórica deu origem a essas mesmas técnicas ${ }^{(14)}$.

A cidadania, teoricamente assentada na igualdade formal, aponta para a desigualdade real como expressão de uma universalidade abstrata.. Esta tem sido a aparência do real. A igualação abstrata de todos perante a lei, impede que, no plano de direito, as desigualdades sociais se expressem. A eliminação das desigualdades torna possível apresentar tudo e todos submetidos às mesmas regras.

Cidadania e qualidade de vida dos indivíduos portadores de transtornos psíquicos, no mundo globalizado, é pensada como uma determinação abstrata da sociedade, ocultando suas determinações reais, apontando para uma forma específica de convivência contraditória, servindo para integrar esses indivíduos pelo "apagamento" de suas diferenças.

\section{PARANÃO CONCLUIR:}

\section{A (RE)INVENÇÃO DO LOUCO}

Qualquer proposta inovadora para superação da realidade aqui apresentada deve pautar-se na busca de uma sociedade marcada pela
Cidadania e qualidade de vida dos portadores de transtornos psiquiátricos: contradições e racionalidade 
Josicélia Dumêt Fernandes Maria Rita Oliveira Juliana Fernandes
Recebido: 23/04/2002 Aprovado: 28/05/2003

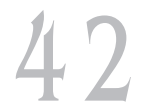

Rev Esc Enferm USP 2003; 37(2): 35-42. equidade, pela equalização das oportunidades, reduzindo as diferenças sociais vividas pelos portadores de necessidades especiais (necessidades especiais - pessoas portadoras de deficiências e que, em função de suas particularidades e suas diferenças, enfrentam barreiras para participar ativamente da sociedade - onde se incluem os portadores de transtornos psíquicos), tornando-os verdadeiros cidadãos de direitos, como está garantido no Art. $6^{\circ}$ da nossa Constituição - " direito à educação, à saúde, ao trabalho, ao lazer, à segurança...", tendo a garantia do exercício da cidadania e melhoria da qualidade de vida.

Não há como superar as contradições anteriormente apresentadas, a não ser produzindo um novo problema. Uma nova maneira de elaborar os desafios da cidadania e da loucura que possam prescindir dos pressupostos racionalistas, universalistas, essencialistas e mentalistas que ainda impregnam essas noções.

Nesse sentido, importa fecundar a idéia da democracia como invenção permanente e reconhecer que produzir novos vocabulários, novas práticas subjetivas é indispensá-

\section{REFERÊNCIAS}

(1) Dallari DA. Estado de direito e cidadania. Univ. Soc. 1997; 14: 5-7.

(2) Vieira L. Cidadania e globalização. Rio de Janeiro: Record; 1999.

(3) Piovesan F. Temas de direitos humanos. São Paulo: Max Limonad; 1998.

(4) Sawaia BB. Cidadania, diversidade e comunidade: uma reflexão psicossocial. In: Spink MJP organizador. A cidadania em construção: uma reflexão transdisciplinar. São Paulo: Cortez; 1994. p. 147-57

(5)Alves JED. Democracia e ações afirmativas. Univ. Soc 1999; 9 (20): 71-75.

(6) Birman J. A cidadania tresloucada: notas introdutórias sobre a cidadania dos doentes mentais. In: Bezerra Jr B, Amarante P organizadores. Psiquiatria sem hospício: contribuições ao estudo da reforma psiquiátrica. Rio de Janeiro: Relume Dumará; 1993. p. 71-90.

(7) Rocha R. Enfermagem psiquiátrica: que papel é este? Rio de Janeiro: Te Corá/IFB; 1994.

(8) Fernandes JD, Sadigursky D, Tavares J, Oliveira MR. O saber e o fazer no processo de formação do enfermeiro de saúde mental. [Apresentado ao IV Seminário Nacional de Diretrizes Curriculares para a Educação em Enfermagem no Brasil; 2000, abril 24-27; Fortaleza]. vel para a construção de uma sociedade mais tolerante. Uma sociedade em que a noção de cidadania implique não apenas o reconhecimento de direitos ou proteção da singularidade, mas um processo ativo de ampliação da capacidade de todos e de cada um agir de modo livre e participativo e, portanto, onde a loucura não implique impossibilidade.

Deve-se continuar trabalhando intensamente pelo reconhecimento e pela proteção da dignidade da pessoa humana, sem qualquer exclusão ou discriminação. Nesse sentido, deve-se desenvolver um trabalho no sentido da extensão da CQV para os portadores de transtornos mentais. Deve-se continuar lutando pela cidadania porque este é um conceito útil de liberdade e igualdade dos seres humanos, mas sem perder de vista que enquanto houver pessoas excluídas da cidadania, não poderá existir sociedade democrática ${ }^{(1)}$.

Nesse panorama, é preciso pensar ou repensar a práxis dos profissionais do setor saúde mental, tendo presente a necessidade de participação coletiva desses trabalhadores e do seu potencial de responsabilidade na viabilização do espaço de construção da cidadania.
(9) Amarante P. Algumas reflexões sobre ética, cidadania e desinstitucionalização na reforma psiquiátrica. Saúde debate 1994; 45: 43-46.

(10) Amarante P. Loucura e ação cultural: desinstitucionalização e reforma psiquiátrica no Brasil. In Anais $49^{\circ}$ Congresso Brasileiro de Enfermagem; 1997 dezembro 7-12; Belo Horizonte. Belo Horizonte: ABEN/MG, 1997. p. 289-308.

(11) Fagundes P. Desinstitucionalização da assistência psiquiátrica: algumas questões cruciais. $\mathrm{J}$ bras psiquiatr 1998; 47 (4):163-8.

(12) Habermas J. O discurso filosófico da modernidade. Lisboa: Publicações Dom Quixote; 1990.

(13) Sassaki R. Inclusão: construindo uma sociedade para todos. Rio de Janeiro: WVA; 1997.

(14) Bezerra Jr B. Cidadania e loucura: um paradoxo? In: Bezerra Jr B, Amarante P organizadores. Psiquiatria sem hospício: contribuições ao estudo da Reforma Psiquiátrica. Rio de Janeiro(RJ): Relume Dumará; 1993. p. $113-126$

(15) Basaglia F. A instituição negada. Rio de Janeiro: Graal; 1985. 